Acta Technologica Agriculturae 2

Nitra, Slovaca Universitas Agriculturae Nitriae, 2021, pp. 55-60

\title{
DEVELOPMENT OF A PILOT SOIL-WATER BALANCE MODEL FOR DETERMINATION OF PROBABILITY OF A WORKING DAY FOR RICE HARVESTING
}

\author{
Mahdi KHANI*, Seyyed Hossein PAYMAN, Nader PIRMORADIAN \\ University of Guilan, Rash, Iran
}

\begin{abstract}
The probability of a working day is the ratio of workable days to the total available days in a working season for the intended operation. Soil moisture is the most important limiting factor in terms of rice harvesting. Therefore, to determine the PWD for this operation, a model was developed to estimate the soil moisture based on soil-water balance. To calibrate and validate the model, the soil moisture was monitored in the paddy field of the University of Guilan during the rice harvest seasons in 2017 and 2018. The calibration process was performed by applying a decreasing ratio, i.e. the senescence factor $(\alpha)$, at a daily evapotranspiration rate compared to that of previous day. At the validation stage, the simulated soil moisture contents were compared with measured values, which indicated a good model accuracy (NRMSE $=6.53 \%$ ) of the soil moisture estimation. Therefore, this model can be used for the rice harvesting operation feasibility evaluation and PWD calculation.
\end{abstract}

Keywords: soil moisture; trafficability; evapotranspiration; agricultural planning

Accurate information on the time available for operations is essential for planning agricultural operations and determining the required working capacity of agricultural machinery. Each agricultural operation is usually limited to a specific timeframe, but factors such as adverse environmental conditions can cause the loss of days in the working season. The ratio of working days to total days during the working season is known as the probability of a working day (PWD). This parameter is used in calculation of minimum and optimum capacities of needed machines, and timeliness cost of operations. To determine the PWD or number of workdays, it is important to determine the feasibility of operations during a specific period. Therefore, the feasibility of operations is examined separately for each day and period. In rice harvesting, the ripening of rice grains determines the time for operation beginning. The end time is also determined by ear drying and increased seed fall. On certain days during this period, it is impossible to perform the harvest due to unsuitable conditions. Huang et al. (2017) identified harvest time as one of the most important factors in grain loss.

Factors that may prevent rice harvest include soil moisture and panicle moisture. Modern rice combine harvesters can harvest and thresh panicles with relatively high moisture content. Therefore, the only parameter considered to influence the feasibility of rice harvesting operations is soil moisture. In this regard, the harvester should be able to enter the field and move through the field easily; i.e., the field must be trafficable. Trafficability is the capacity of soil to support and withstand traffic with negligible soil structural damage and no adverse effects on crop yield (Rounsevell and Jones, 1993).
Moisture content at field capacity (Cooper et al., 1997; Simalenga and Have,1992; Rutledge and McHardy, 1968) and plastic limit (Dexter and Bird, 2001) are the most common soil moisture thresholds used to examine the feasibility of operations. However, a certain limit cannot be specified for all conditions and soils, because the interaction between soil and machine depends on machine characteristics including machine mass (McPhee et al., 2020), and size and pressure of tire (Antille et al., 2013; Stevens et al., 2016), as well as soil properties including texture, organic matter content and bulk density. Carranza et al. (2019) stated that root growth can also affect soil trafficability. Therefore, the best way to determine the trafficability limit is experimental investigation.

The primary method to determine the PWD is to survey the real situation in order to directly examine the possibility of performance of operations for several years. Despite its high accuracy, this method is very costly and time-consuming, and the results can only be applied to the climate, soil, and particular crop under consideration.

The most common method is to estimate the conditions for assessing the feasibility of operations in the previous years. In this method, field conditions in the working season are estimated using the meteorological data and other required data from previous years. Then, the feasibility of operations is judged by comparing the estimated conditions and workability criteria. Soil moisture is one of the most important limiting factors in most agricultural operations. This parameter is estimated using soil-water balance models. This method has been used for tillage (Abdulsalam et al., 2017; Cooper et al., 1997; Khani et al., 2011; Simalenga and Have,1992), as well as planting and harvesting of corn (Jahun et al., 2014).

Contact address: Mahdi Khani, University of Guilan, Faculty of Agricultural Sciences, Department of Agricultural Mechanization Engineering, Rash, Iran; e-mail: mahdikhani@guilan.ac.ir 
World rice production amounts to approx. 618 million tons per year (Rahimi-Ajdadi et al., 2018), but no research has investigated the workdays of the rice crop. In rice farming, harvesting is the most sensitive period in terms of operation time. Improper knowledge about the available time leads to inappropriate timing of operations and considerable economic losses. Existing soil-water balance models are generally developed to estimate the water requirement of plants during the growing season and are not suitable for estimation of the soil moisture during harvest season. In particular, the gradual senescence of rice plants can be a source of error in the evapotranspiration calculation. Even after developing a suitable model, it should be calibrated to improve the estimation accuracy. In this study, a model was developed for estimating the soil moisture during the rice harvesting period and calculating the PWD by comparing the moisture content estimated with a trafficability limit. Then, the model efficiency and the reliability of its output data were evaluated by a validation test.

\section{Material and methods}

\section{Model structure}

According to the mass conservation law, the amount of water entering the soil profile is equal to the algebraic sum of released and stored water. The moisture output and input to the soil profile can be calculated using meteorological and soil properties data. In this manner, new moisture content can be attributed to the soil by adding the initial soil moisture. This cycle continues repeatedly, and soil moisture is determined throughout the days under consideration. The general structure of the model is as follows:

$$
\theta_{i+1}=\theta_{i}+P_{i}-D_{i}-R_{i}-E T_{i}
$$

where:

$$
\begin{array}{ll}
\theta_{i} \quad \text { - soil water content at the } & \text { beginning of a given time step } \\
P_{i}- & \text { rainfall (or irrigation) } \\
D_{i}- & \text { drainage } \\
R_{i}- & \text { runoff } \\
E T_{i}- & \text { evapotranspiration at the given } \\
& \text { time step }
\end{array}
$$

$\theta_{i+1}$ - soil water content at the end of this time step or at the beginning of the next time step

Appropriate workdays are determined after calculating the soil moisture and comparing it with the moisture limit. The PWD for a period is obtained by dividing the number of workdays by total amount of period days. The general model flowchart is shown in Fig. 1.

To calculate the evapotranspiration, this parameter is first obtained for the

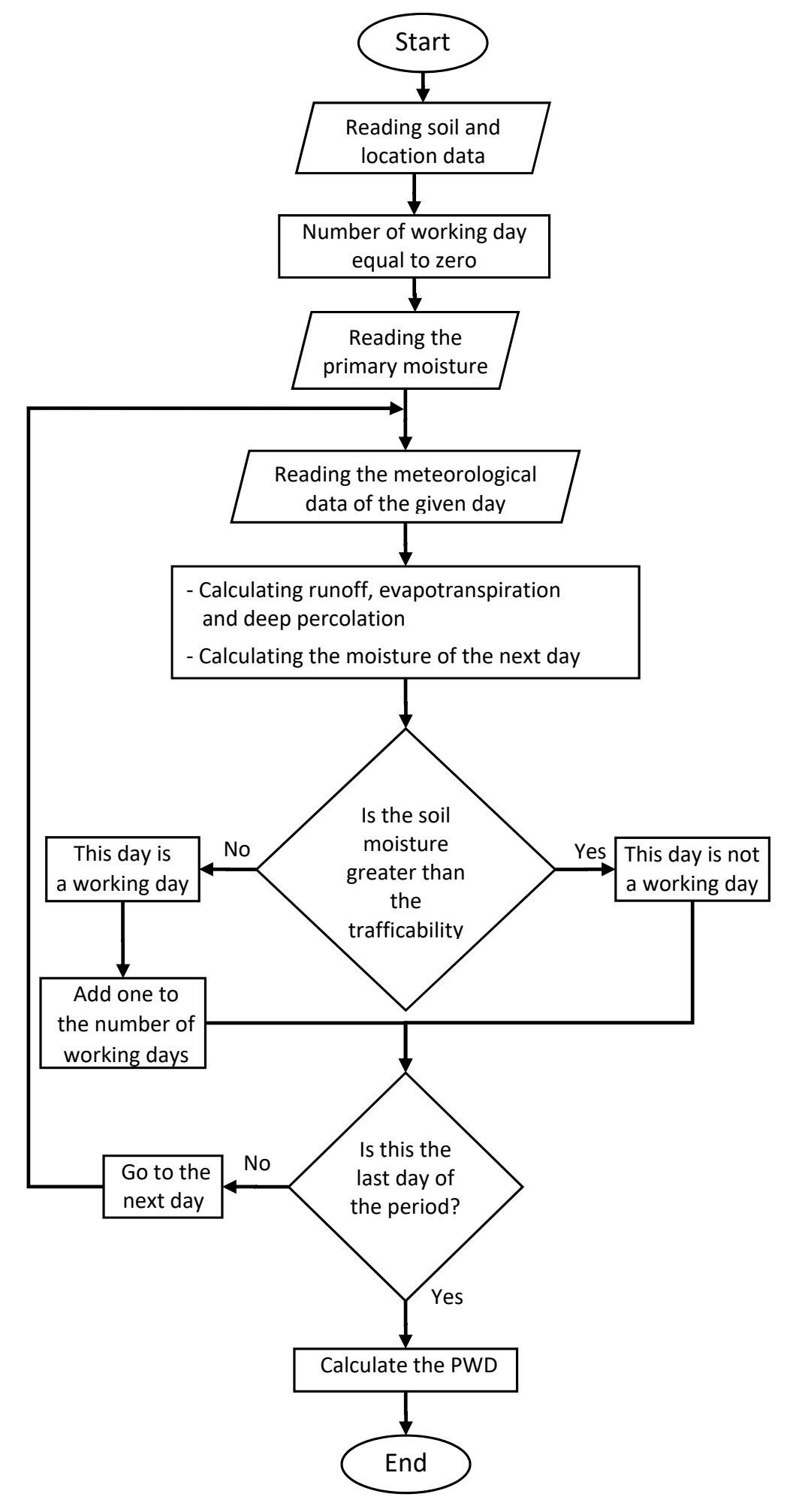

Fig. 1 General model flowchart 
reference plant (grass) under standard conditions using the Penman-Monteith equation (Allen et al., 1998) (Eq. 2):

$$
E T_{0}=\frac{0.408 \Delta\left(R_{n}-G\right)+\gamma \frac{C_{n}}{T+273} u_{2}\left(e_{s}-e_{a}\right)}{\Delta+\gamma\left(1+C_{d} u_{2}\right)}
$$

where:

$$
\begin{aligned}
& E T_{0} \text { - reference evapotranspiration }\left(\mathrm{mm} \cdot \text { day }^{-1}\right. \text { for daily } \\
& \text { time step) } \\
& R_{n} \quad \text { - net radiation at the crop surface }\left(\mathrm{MJ} \cdot \mathrm{m}^{-2} \cdot \text { day }^{-1}\right) \\
& G \quad-\text { soil heat flux density }\left(\mathrm{MJ} \cdot \mathrm{m}^{-2} \cdot \text { day }^{-1}\right) \\
& T \quad \text { - mean daily air temperature at } 2 \mathrm{~m} \text { height }\left({ }^{\circ} \mathrm{C}\right) \\
& u_{2} \quad-\text { wind speed at } 2 \mathrm{~m} \text { height }\left(\mathrm{m} \cdot \mathrm{s}^{-1}\right) \\
& e_{s} \quad-\text { saturation vapour pressure }(\mathrm{kPa}) \\
& e_{a} \quad-\text { actual vapour pressure }(\mathrm{kPa}) \\
& e_{s}-e_{a}-\text { saturation vapour pressure deficit }(\mathrm{kPa}) \\
& \Delta \quad \text { - slope vapour pressure curve }\left(\mathrm{kPa} \cdot{ }^{\circ} \mathrm{C}^{-1}\right) \\
& \gamma \quad-\text { psychrometric constant }\left(\mathrm{kPa} \cdot{ }^{\circ} \mathrm{C}^{-1}\right) \\
& \text { the } C_{n} \text { and }{ }_{C d} \text { constants for daily values are } 900 \text { and } \\
& 0.34 \text {, respectively }
\end{aligned}
$$

Information on the calculation of parameters of this equation is given in Allen et al. (1998). To obtain the potential evapotranspiration $\left(E T_{p}\right)$ of the plant under consideration, the reference evapotranspiration $\left(E T_{0}\right)$ must be multiplied by the corresponding crop coefficient $\left(K_{c}\right)$ (Eq. 3 ). The value of this coefficient is determined based on the type of plant and its growth stage. A value of 0.6 was considered for this coefficient, since rice is in the late stage of growth at the time of harvest (Allen et al., 1998).

$$
E T_{p}=K_{c} \cdot E T_{0}
$$

As long as soil moisture is sufficient, atmospheric parameters determine the evapotranspiration rate. When the plant starts to lose access to the readily available water, the actual amount of evapotranspiration will be less than its potential value. To convert $E T_{p}$ into actual evapotranspiration $\left(E T_{a}\right)$, a correction factor - the stress coefficient $\left(K_{s}\right)$ - is used:

$$
E T_{a}=K_{s} \cdot E T_{p}
$$

The stress factor is obtained as follows:

$$
K_{s}=\frac{T A W-D_{r}}{T A W-R A W}
$$

where:

TAW - total available water in the root zone (obtained by multiplying the difference in moisture content at the field capacity (FC) and permanent wilting point (PWP) in the effective root depth)

RAW - readily available water, which is considered to be 0.4 (Allen et al., 1998) of TAW due to the shallow root of rice in the paddy field

$D_{r} \quad$ - root zone depletion. These parameters are expressed in millimetres of water. The Eq. 5 is applicable after the depletion of $R A W$; prior to this point, the $K_{s}$ is assumed to be equal to 1
The runoff was calculated using the curve number (CN) method (Eq. 6) introduced by the US Soil Conservation Service (SCS, 1972):

$$
R=\frac{(P-0.2 S)^{2}}{P-0.8 S} \text { for } P \geq 0.2 S
$$

where:

$R \quad-\operatorname{runoff}(\mathrm{mm})$

$P \quad$ - precipitation $(\mathrm{mm})$

$$
S=\frac{25,400}{C N}-254
$$

where:

$S \quad$ - potential maximum retention $(\mathrm{mm})$

The CNvalue (i.e., 0 to 100) depends on soil characteristics, crop cover, and hydrological conditions.

When the soil moisture in surface layer exceeds the FC, moisture transfer to soil lower layers occurs due to deep percolation. Due to the presence of hardpan, a constant rate is considered for deep percolation in paddy soils. In this model, the percolation rate is considered a model input that can be obtained from different references according to the soil texture, e.g. Razavipour et al. (2005) measured this parameter in different types of soils in the Guilan province. The rate of deep percolation in this study was determined based on their work.

Subsequently, the soil moisture can be obtained by having the initial soil moisture content using the soilwater balance equation. This process continues from the beginning to the end of the simulation, and soil moisture is calculated throughout the days of the considered period. The trafficability limit as the model input is determined by the user. If soil moisture is less than the trafficability limit, that day will be considered as a workable day; otherwise, the operation is not possible. In this study, the moisture content, in which the farmer could bring a combine harvester to the field for the first time ( 44.8 vol. $\%$ for the validation field) and start harvesting, was considered to be a trafficability limit.

The model was coded in VBA (Visual Basic for Applications) - the MS-Office suite programming language. Input data are introduced into the Excel spreadsheet and output data are also displayed in the same software.

\section{Model calibration}

The time period considered in this study is the last days of rice plant lifetime when the plant evapotranspiration capacity decreases due to the leaf senescence onset. Since the effects of plant leaf senescence on its transpiration have not been well discussed by scientists, this issue was taken into account in model calibration process. To calibrate the model, a comparison was made between simulated and measured soil moisture values.

In this regard, firstly, the process of soil moisture changes in rice harvest season was simulated using the model for a plot of land at the Faculty of Agricultural Sciences, University of Guilan. Next, soil samples were collected to determine the soil characteristics, such as texture, bulk density, and moisture content at FC, and PWP. 
Meteorological data in 2017 were obtained from the Rasht Agricultural Synoptic Station in the vicinity of the field under study. The soil bulk density, moisture content at FC, and soil texture were measured by a sampling cylinder, a pressure plate apparatus, and hydrometer method, respectively. The moisture content at PWP was estimated by the percentage of soil particles and bulk density using the Rosetta software.

The rice (Var. Hashemi) was harvested on August 20. On July 24 , the first moisture data were collected in the field to determine the initial moisture content at the stimulation onset.

The simulated results and measured data were compared statistically using normalized root-mean-square error (NRMSE).

At the ripening period onset and with senescence of certain plant leaves, its transpiration capacity and subsequently the field potential for evapotranspiration decrease each day relative to the previous day by a coefficient. To incorporate this effect in the model, daily $E T_{p}$ was calculated as follows:

$$
E T_{p r}(i)=E T_{p}(i) \times(1-\alpha)^{i-1}
$$

where:

$E T_{p}(i)$ - potential evapotranspiration on the $i^{t \text { th }}$ day regardless of plant senescence

$E T_{p r}(i)$ - potential evapotranspiration on the $i^{\text {th }}$ day taking into account the plant senescence

$i \quad-$ number of given days

$\alpha \quad-$ ratio of decreasing of evapotranspiration each day to its value in the previous day $(0 \leq \alpha \leq 0.1)$

Therefore, rather than obtaining $E T_{a}$ directly from $E T_{p}$ the effects of plant senescence are first considered on $E T_{p}$, followed by obtaining $E T_{a}$ (which depends on soil moisture conditions) from the modified potential evapotranspiration $\left(E T_{p r}\right)$.

Different values of $\alpha$ (1-10\%) were considered for calibration. Subsequently, the $\alpha$ value showing the highest agreement between the simulated and measured data (minimum NRMSE value) was considered an appropriate value of plant senescence factor for the studied conditions.

\section{Model validation}

The model performance should be ensured for practical use. To this end, a validation test was also performed to compare simulation results with measured data at a time and location different from the calibration test. The test was carried out at another field of the University of Guilan during the rice harvest period in 2018. For these purposes, five samples per day were collected as experimental replicates. The samples were taken only from the depth of $15 \mathrm{~cm}$. Sampling started on 25 July 2018 and continued until 24 August 2018.

To statistically compare the results and determine the model inputs, the same procedure used in calibration test was also employed in this test. The default senescence factor $(\alpha)$ applied to this test was determined according to the calibration test results.

\section{Results and discussion}

\section{Soil test}

The soil texture test results and measurement of its hydraulic parameters for the studied fields during calibration and validation steps are shown in Table 1.

Table 1 Soil properties of fields used in the calibration and validation tests

\begin{tabular}{|c|c|c|}
\hline $\begin{array}{c}\text { Validation } \\
\text { field }\end{array}$ & $\begin{array}{c}\text { Calibration } \\
\text { field }\end{array}$ & $\begin{array}{c}\text { Soil } \\
\text { properties }\end{array}$ \\
\hline 57.2 & 45.2 & clay (\%) \\
\hline 30.2 & 46.3 & silt (\%) \\
\hline 12.6 & 8.5 & sand (\%) \\
\hline clay & silty clay & soil texture \\
\hline 1.5 & 1.5 & deep percolation rate $\left(\mathrm{mm}^{-12}{ }^{-1}\right)$ \\
\hline 1.12 & 1.13 & bulk density $\left(\mathrm{g} \cdot \mathrm{cm}^{-3}\right)$ \\
\hline 36.7 & 37.6 & gravimetric moisture at FC (\%) \\
\hline 19.5 & 16.4 & gravimetric moisture at PWP (\%) \\
\hline
\end{tabular}

\section{Calibration}

Correlation values between the estimated and measured moisture for different values of the senescence factor during calibration test are shown in Fig. 2. Taking into account that the senescence factor yields a more reasonable estimate of the evapotranspiration rate as the most important component of soil-water balance, it improves the correlation between the simulated and measured data. As shown in Fig. 2, the moisture estimation accuracy enhances with increasing $\alpha$ (senescence factor) until the highest correlation is achieved between the measured and estimated data. Excessive increase in $\alpha$ leads to the underestimation of evapotranspiration and reduces the moisture estimation quality. The highest agreement (NRMSE $=5.38 \%$ ) between simulated and measured data was obtained with an $\alpha$ of 0.05 . As a result, an $\alpha$ of $5 \%$ was selected for the basis of this model in order to correct the evapotranspiration calculation and estimate the soil moisture content. In the following conduction, the validation test and PWD calculations were performed accordingly.

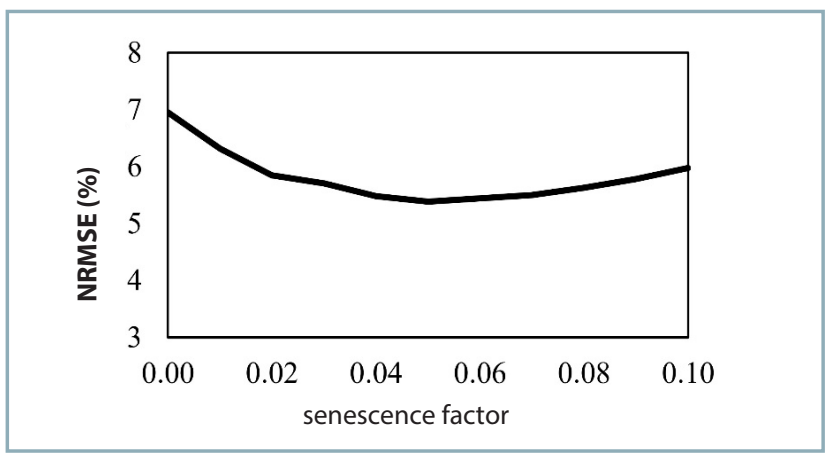

Fig. 2 NRMSE values obtained by taking into account different values for the senescence factor $(\alpha)$ in the calibration test 


\section{Validation}

The validation test (with an $\alpha$ of 0.05 ) yielded an NRMSE value of $6.53 \%$, indicating the acceptable model performance in estimating the soil moisture.

Fig. 3 shows the trend of moisture changes in simulated and measured conditions in non-calibrated (without senescence factor) and calibrated modes.

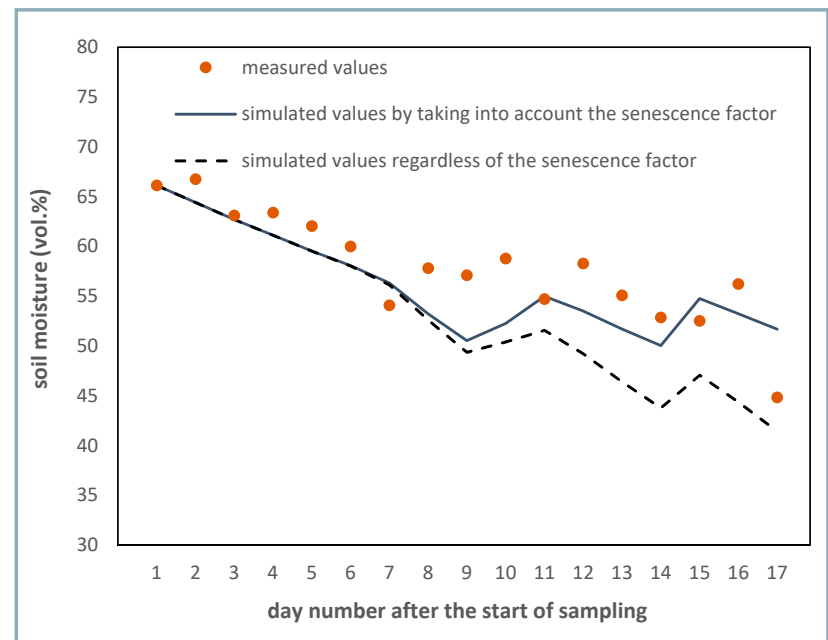

Fig. 3 Comparison of simulated and measured moisture in the validation test

According to Fig. 3, the simulated and measured data are much consistent at the beginning of period, but the difference between results grows in the final days. The main reason for this seems to be the senescence of certain plant leaves and decreased transpiration. However, evaporation from the soil surface was not affected by this process.

The model calibration and considerations of the dropped leaf transpiration capacity due to leaf senescence led to an increased agreement between the measured and simulated data, particularly in the final days prior to rice harvest. There are several moisture changes with upward trend due to rainfall on certain days.

Considering the different times and locations of calibration and validation tests, this model can be also used in other rice fields with similar conditions to those of these tests, and there is no need to repeat the calibration test for each field.

A good model performance in validation test due to the modifications in calibration test does not mean a constant senescence factor under all conditions. The calibration test must be rerun if the model is to be used for different climates and possibly different rice varieties. It can, however, be deduced that it is possible to use the senescence factor obtained here to accurately calculate the evapotranspiration of rice plant and soil moisture. As a result, a realistic estimate of the feasibility of rice harvesting operations can be obtained under majority of conditions similar to those presented here.

Instead of comparing the measured and simulated soil moistures, Rotz and Harrigan (2005) and Yousif et al. (2014) compared the number of observed workdays with the estimated ones to evaluate their models.
The advantage of this method is that it simultaneously includes the accuracy of moisture estimation and the accuracy of determining the moisture threshold. However, it may lead to a misunderstanding about the model reliability.

There may be a significant difference between the simulated and actual soil moisture on a given day, but due to the selected moisture threshold, the model simulation result and field observations are the same in terms of operation feasibility.

Furthermore, soil moisture underestimation in particular parts of a working period can be offset by overestimation in other parts of the period, since this method takes into account only the total number of working days in the entire working period, suggesting that this method can exaggerate the accuracy of the model.

\section{Conclusion}

The model developed has an acceptable performance to determine the PWD. Therefore, it can be used in many rice fields that do not significantly differ from the studied field in terms of climatic conditions. It is recommended to conduct further studies on the climate change impact on the time available for operations. The methods proposed for PWD determination implicitly assume that average weather conditions in forthcoming years are similar to those of previous years. Nonetheless, climate change caused by greenhouse gas emissions may affect the accuracy of calculations for the number of workdays. However, certain efforts have been made to investigate the effect of climate change on the PWD (Cooper et al., 1997). Nevertheless, more state-of-the-art and extensive studies are required to determine the degree of changes and their effects on available working time.

It is recommended to study the plant senescence process using more accurate and generalizable methods. The plant dropped transpiration in the final period of plant establishment can be estimated more accurately if more comprehensive and accurate equations are obtained from the yellowing process of plant leaves. In such a manner, it would be possible to expand the model application scope.

With yellowing of the rice plant, the field soil drying process drastically decreases through evapotranspiration. Accordingly, in years with concerns about limited available workdays, field planning should be in such a way that the last irrigation can be done earlier. In this case, the evaporative capacity of the plant is used before drying its leaves, thereby accelerating the process of soil moisture reduction.

Models for PWD determination are developed for a particular plant and operation and are rarely used for other conditions. Therefore, the development of a comprehensive model that can estimate the PWD in majority of conditions can be one of the primary objectives of future studies. In this regard, it is recommended to develop an efficient model that can work for different plants (with or without hardpan), bare soil, row crops, etc.

\section{Acknowledgements}

The authors would like to acknowledge the Faculty of Agricultural Science, University of Guilan, for their support and contribution to this study. 


\section{References}

ABDULSALAM, M. - ISIAKA, M. - DALHA, I. B. - DALHAT, M. K. 2017. Performance evaluation of computer-based suitable field workdays model. In Bayero Journal of Engineering and Technology, vol. 12, no. 1, pp. 52-66.

ALLEN, R. G. - PEREIRA, L. S. - RAES, D. - SMITH, M. 1998. Crop evapotranspiration: Guidelines for computing crop water requirements. In FAO Irrigation and Drainage Paper No 56. Food and Agriculture Organization, Land and Water. Rome, Italy.

ANTILLE, D. L. - ANDSORGE, D. - DRESSER, M. L. - GODWIN, R. J. 2013. Soil displacement and soil bulk density changes as affected by tire size. In Transactions of the ASABE, vol. 56, no. 5, pp. 1683-1693. CARRANZA, C. - BENNINGA, H. J. - VELDE, R. V. D. - PLOEG, M. V. D. 2019. Monitoring agricultural field trafficability using Sentinel-1. In Agricultural Water Management, vol. 224, 105698.

COOPER, G. - McGECHAN, M. B. - VINTEN, A. J. A. 1997. The influence of a changed climate on soil workability and available workdays in Scotland. In Journal of Agricultural Engineering Research, vol. 68 , no. 3, pp. 253-269.

DEXTER, A. R. - BIRD, N. R. A. 2001. Methods for predicting the optimum and the range of soil water contents for tillage based on the water retention curve. In Soil \& Tillage Research, vol. 57, pp. 203-212.

HUANG, T. - LI, B. - SHEN, D. - CAO, J. - MAO, B. 2017. Analysis of the grain loss in harvest based on logistic regression. In Procedia Computer Science, vol. 122, pp. 698-705.

JAHUN, B. G. - IYA, S. A. - ABUBAKAR, Y. 2014. Estimation of suitable field workday of planting and harvesting operations of maize production in Bauchi State Nigeria. In European Journal of Food Science and Technology, vol. 2, no. 1, pp. 8-18.

KHANI, M. - KEYHANI, A. - PARSINEJAD, M. - ALIMARDANI, R. 2011. Verification and sensitivity analysis of a model for determination of probability of a working day for tillage. In International Agrophysics, vol. 25, no. 1, pp. 27-35.

McPHEE, J. E. - ANTILLE, D. L. - TULLBERG, J. N. - DOYLE, R. B. BOERSMA, M. 2020. Managing soil compaction - A choice of lowmass autonomous vehicles or controlled traffic? In Biosystems Engineering, vol. 195, pp. 227-241.
RAHIMI-AJDADI, F. - ASLI-ARDEH, A. A. E. - AHMADI-ARA, A. 2018. Effect of varying parboiling conditions on head rice yield for common paddy varieties in Iran. In Acta Technologica Agriculturae, vol. 21, no. 1, pp. 1-7.

RAZAVIPOUR, T. - YAZDANI, M. R. - MOUSAVI, S. F. 2005. Measuring water deep percolation in different soil textures of paddy fields in the growing season of rice. In Journal of Agricultural Natural Resources Science of Khazar, vol. 3, no. 4, pp. 1-9. (in Farsi with English abstract)

ROTZ, C. A. - HARRIGAN, T. M. 2005. Predicting suitable days for field machinery operations in a whole farm simulation. In Applied Engineering in Agriculture, vol. 21, no. 4, pp. 563-571.

ROUNSEVELL, M. D. A. - JONES, R. J. A. 1993. A soil and agroclimatic model for estimating machinery workdays: the basic model and climatic sensitivity. In Soil \& Tillage Research, vol. 26, no. 3, pp. 179-191.

RUTLEDGE, P. L. - MCHARDY, F. V. 1968. The influence of the weather on field tractability in Alberta. In Canadian Agricultural Engineering, vol. 10, no. 2, pp. 70-73.

SIMALENGA, T. E. - HAVE, H. 1992. Estimation of soil tillage workdays in a semi-arid area. In Journal of Agricultural Engineering Research, vol. 51, pp. 81-89.

STEVENS, M. T. - MCKINDLEY, G. B. - VAHEDIFAR, F. 2016 A comparison of ground vehicle mobility analysis based on soil moisture time series datasets from WindSat, LIS, and in situ sensors. In Journal of Terramechanics, vol. 65, pp. 49-59.

USDA-SCS. 1972. Soil Conservation Service National Engineering Handbook. United States Department of Agriculture.

YOUSIF, A. E. A. - DAHAB, M. H. - RAMLAWI, H. R. El. - FARID ELTOUM, A. E. 2014. A computer system for prediction of farm machinery workable days in rain-fed areas of Sudan. In International Journal of Engineering \& Scientific Research, vol. 2, no. 11, pp. 17-23. 